\section{A E E T}

ASOCIACIÓN ESPAÑOLA

DE ECOLOGÍA TERRESTRE

\title{
Los precedentes y las respuestas de los árboles a sequías extremas revelan los procesos involucrados en el decaimiento de bosques mediterráneos de coníferas
}

\author{
(1) ARAID-Instituto Pirenaico de Ecología (CSIC). Avda. Montañana 1005, Apdo. 202, 50192 Zaragoza. España. \\ (2) Instituto Pirenaico de Ecología (CSIC). Avda. Montañana 1005, Apdo. 202, 50192 Zaragoza. España. \\ (3) Faculty of Forestry Sciences, Agricultural University of Tirana, 1029, Kodër-Kamëz, Tirana, Albania \\ * Autor de correspondencia: J.J. Camararo [jicamarero@ipe.csic.es]
}

> Recibido el 12 de noviembre de 2012, aceptado el 30 de noviembre de 2012.

Camarero, J.J., Sangüesa Barreda, G., Alla, A.Q.. González de Andrés, E., Maestro Martínez, M.,Vicente-Serrano, S.V. (2012). Los precedentes y las respuestas de los árboles a sequías extremas revelan los procesos involucrados en el decaimiento de bosques mediterráneos de coníferas. Ecosistemas 21(3):22-30. Doi.: 10.7818/ECOS.2012.21-3.04

¿Qué determina la vulnerabilidad de las especies de árboles frente a eventos climáticos extremos en el contexto actual de calentamiento global? Sabemos que las sequías severas contribuyen al decaimiento del bosque pero desconocemos los procesos involucrados en el declive de crecimiento y la pérdida de vigor del árbol que pueden conducir a su muerte. Para profundizar en estos procesos combinamos datos retrospectivos de crecimiento secundario, obtenidos mediante dendrocronología, y variables funcionales potencialmente indicadoras de cambios de vigor (frondosidad, producción de albura, cambios en las concentraciones de carbohidratos no estructurales en acículas y albura del tronco) en bosques mediterráneos afectados por decaimiento inducido por sequía. Evaluamos las respuestas de tres especies de árboles (Abies alba, Pinus sylvestris y Pinus halepensis) a la sequía extrema del año 2012 caracterizada mediante un índice de sequía que considera la temperatura. En primavera y verano del año 2012 la sequía fue muy intensa debido a que las elevadas temperaturas máximas condujeron a condiciones de aridez que carecen de precedentes similares desde 1950. En las tres especies los árboles menos frondosos (más defoliados) formaban menos albura y ésta contenía una menor concentración de azúcares solubles que en los árboles más frondosos. Los árboles más defoliados presentaron también mayor similitud de crecimiento secundario entre años consecutivos que los poco defoliados. Los patrones de crecimiento difirieron entre especies y sugieren que en $P$. sylvestris el decaimiento responde a sequías extremas recurrentes durante el siglo pasado, mientras que $A$. alba y $P$. halepensis muestran patrones correspondientes a un declive durante la pasada década relacionado con el aumento de temperaturas que ha producido el decaimiento de individuos que durante episodios climáticamente benignos pasados mostraron altas tasas de crecimiento. Los diversos patrones descritos indican la necesidad de definir conceptos como la muerte del árbol o su recuperación post-decaimiento dentro de un marco de investigación objetivo, cuantitativo y verificable.

Palabras clave: calentamiento climático, carbohidratos no estructurales, defoliación, dendroecología, evento extremo, índice de sequía, mortalidad.

Camarero, J.J., Sangüesa Barreda, G., Alla, A.Q,. González de Andrés, E., Maestro Martínez, M.,Vicente-Serrano, S.V. (2012). The precedents and the responses of trees to extreme droughts reveal the processes involved in the die-off of Mediterranean conifer forests. Ecosistemas 21(3):000-000. Doi.: 10.7818/ECOS.2012.21-3.04

What drives the tree species' vulnerability against extreme climatic events within the current context of global warming? We are aware that severe droughts contribute to forest die-off but we do not know the processes involved in the growth decline leading to a loss of tree vigour, which may ultimately cause tree death. To get a better understanding of those processes we combine retrospective secondary-growth data, obtained using dendrochronology, and functional variables which may be potential indicators of changes in vigour (crown density, sapwood production, changes in the concentrations of non-structural carbohidrates in needles and stem sapwood) in Mediterranean forests affected by drought-induced die-off. We evaluate how three tree species (Abies alba, Pinus sylvestris, Pinus halepensis) responded to the extreme drought which occurred in 2012 by calculating a drought index which takes into account the effect of temperature. In spring and summer 2012 the drought was very intense because the high maximum temperatures caused very arid conditions which were unprecedented since 1950. Considering the three species, the trees with less dense crowns (more defoliated) formed less sapwood, presenting a lower concentration of soluble sugars than less defoliated trees did. The more defoliated trees were also characterized by showing a higher persistence in radial growth than less defoliated trees. The growth patterns differed among species. These patterns suggest that the $P$. sylvestris die-off was caused by successive and extreme droughts during the past century, whereas $A$. alba and $P$. halepensis growth patterns may correspond to a progressive die-off, which started during the past decade in response to rising temperatures. In the latter two species, declining individuals showed the highest growth rates during past climatically mild periods. The diverse described patterns indicate the need to define concepts such as tree death and post die-off tree recovery within an objective, quantitative and verifiable research framework.

Key words: climate warming, defoliation, dendroecology, drought index, extreme event, mortality, non-structural carbohydrates

\section{Introducción}

El decaimiento del bosque inducido por sequías extremas se está revelando como un fenómeno global aparentemente vinculado al calentamiento climático (van Mantgem et al. 2009, Allen et al
2010, Lloret 2012, Martínez-Vilalta et al. 2012). Este declive en la productividad y el crecimiento puede ir acompañado de un aumento de mortalidad, lo que causa cambios ecosistémicos y altera la composición de las comunidades forestales (Breshears et al. 2005). A su vez el aumento del estrés hídrico puede afectar a cómo los bos- 
ques puedan mitigar o amplificar el cambio climático. Por ejemplo, en zonas semiáridas la mortalidad del arbolado posiblemente aumente la tasa de evaporación del suelo e induzca condiciones microclimáticas más cálidas (Bonan 2008).

Existen aún múltiples interrogantes relacionados con los procesos de decaimiento y mortalidad vinculados a: (i) los factores climáticos desencadenantes (aumento de temperatura y de demanda evaporativa frente al descenso de precipitación), (Adams et al. 2009; Bréda et al. 2006; Williams et al. 2012) (ii) los mecanismos fisiológicos involucrados en el decaimiento y posterior muerte (pérdida brusca de conductividad hidráulica, alteraciones del uso y asignación de carbohidratos) (Sala et al. 2010, McDowell 2011), (iii) la aclimatación o plasticidad en las respuestas a la sequía de especies o individuos que coexisten (Lloret et al. 2012; Anderegg et al. 2012a), y (iv) la respuesta post-sequía en relación a la capacidad de recuperación del crecimiento (Anderegg et al. 2012b). Parte de este desconocimiento surge de la ausencia de una definición sistémica, objetiva y verificable de la muerte del árbol considerando que los árboles son organismos complejos en los que alteraciones en el uso de agua y carbono conducen a una pérdida irreversible de crecimiento (Anderegg et al. 2012a). En este sentido, el crecimiento secundario o radial se ha considerado un buen indicador del vigor a largo plazo del árbol y permite definir cuándo se ha producido un declive acusado en la formación de xilema en respuesta a sequías (Dobbertin 2005; Bigler et al. 2006). Por lo tanto, en este trabajo pretendemos aportar información preliminar sobre los procesos de decaimiento y muerte de los árboles inducidos por la sequía reciente del año 2012 sobre tres especies sometidos a condiciones climáticas Mediterráneas contrastadas (Abies alba, Pinus sylvestris y Pinus halepensis). Para ello caracterizaremos: (i) las condiciones climáticas que acompañan al decaimiento mediante un índice de sequía que integra el efecto de la temperatura, y (ii) los procesos relacionados con dicho decaimiento, incluyendo la pérdida de frondosidad de la copa (defoliación), el declive en el crecimiento radial y cambios en las concentraciones de carbohidratos no estructurales en la albura. Como hipótesis de partida, planteamos que los árboles con mayor probabilidad de muerte mostrarán una menor frondosidad de la copa y un menor crecimiento radial reciente y presentarán unas menores reservas de carbohidratos no estructurales. Consideramos que estos tres indicadores pueden servir para establecer una definición más objetiva y verificable del momento de la muerte del árbol durante un proceso de decaimiento de origen climático.

\section{Material y métodos}

\section{Muestreo de campo}

A finales del año 2011 seleccionamos tres zonas dominadas por las tres especies de estudio: abeto (Abies alba Mill), pino albar (Pinus sylvestris L.) y pino carrasco (Pinus halepensis Mill.). Las tres zonas de estudio se localizaron en bosques situados en Aragón (NE España) y que contenían árboles presuntamente afectados por la sequía, que mostraban defoliación acentuada o estaban muriendo, y árboles aparentemente sanos (Fig. 1, Tabla 1). Es importante mencionar que las tres zonas muestreadas incluían árboles totalmente defoliados que, aparentemente, estaban muertos en el momento del muestreo. La proporción de árboles defoliados era similar a la del entorno (Tabla 1). Todos los bosques estudiados experimentan condiciones climáticas continentales y mediterráneas, ya que en todos ellos el balance hídrico es negativo desde junio hasta agosto, aunque dichas condiciones varían entre húmedas (abeto) a semiáridas (pino carrasco). Los bosques de $P$. sylvestris y $A$. alba se localizan cerca de los límites $S$ y $S O$ de distribución de las respectivas especies, mientras que el bosque de $P$. halepensis se encuentra cerca del límite $O$ de la especie (Fig. 2). En cada bosque muestreamos 38 árboles de cada especie seleccionándolos al azar y separados entre sí por al menos $5 \mathrm{~m}$ abarcando un área de muestreo de entre 0.5 ( $A$. alba, $P$. sylvestris) a 2 ha ( $P$. halepensis). La menor área basimétrica del pinar de carrasco (Tabla 1) provocó
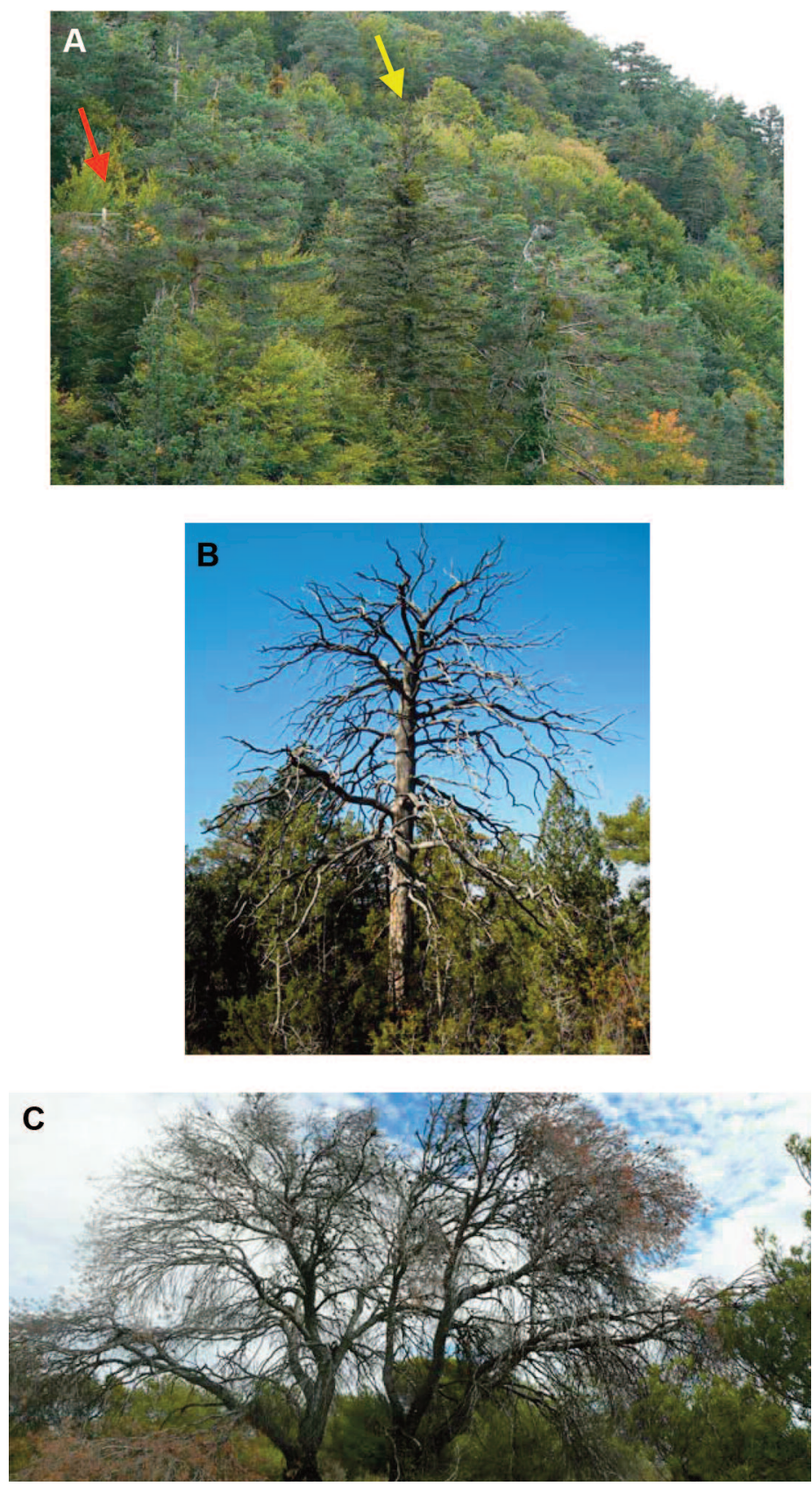

Figura 1. Decaimiento y mortalidad en tres bosques contrastados de coníferas. A. Abetos muertos (flecha roja) o decaídos con abundante muérdago (flecha amarilla) en el Paco Ezpela (Ansó, Huesca). Fotografía tomada el 8 de octubre del 2012. B. Individuo de pino albar muerto por efecto de la sequía en la zona de Corbalán, Teruel. Nótese la ausencia de acículas y de corteza en la parte superior del tronco. Fotografía tomada en julio del 2012. C. Pino carrasco muerto muestreado en el Vedado de Peñaflor. La presencia de acículas rojas en la copa indica una fecha de muerte reciente que los datos dendrocronológicos sitúan en el año 2009, es decir 3 años antes del muestro. Fotografía tomada el 10 de octubre del 2012.

que la distancia media ( $\pm \mathrm{SE}$ ) entre árboles muestreados fuera mayor $(29.2 \pm 4.8 \mathrm{~m})$ que en el caso del abetar $(10.6 \pm 1.5 \mathrm{~m})$ o del bosque de pino albar $(8.5 \pm 1.3 \mathrm{~m})$. Los suelos de los tres sitios de estudio son básicos. El suelo del pinar albar se desarrolla sobre afloramientos calcáreos, mientras que el del abetar está dominado por margas (ver más detalles de la zona en Linares y Camarero 2012) y el del pinar de carrasco está compuesto por una mezcla de arcillas y yesos. En la Tabla 1 se indican las principales características de cada sitio de estudio.

Para cada árbol medimos variables relacionadas con su tamaño (diámetro medido a $1.3 \mathrm{~m}$ de altura, altura total) y vigor (frondosidad de la copa -fracción de copa verde-, abundancia de muérdago, área de albura -ver la estima de esta última variable en el sub-apar- 
Tabla 1. Principales características de cada bosque y especie estudiados. En el caso de algunas variables se muestran los valores medios $( \pm$ error estándar).

\begin{tabular}{|c|c|c|c|}
\hline Sitio (código, localidad, provincia) & $\begin{array}{c}\text { Paco Ezpela } \\
\text { (Hu, Ansó, Huesca) }\end{array}$ & $\begin{array}{c}\text { El Carrascal } \\
\text { (Te, Corbalán, Teruel) }\end{array}$ & $\begin{array}{l}\text { Vedado de Peñaflor } \\
\text { (Z, Peñaflor, Zaragoza) }\end{array}$ \\
\hline Especie & Abies alba & Pinus sylvestris & Pinus halepensis \\
\hline Latitud (N) & $42^{\circ} 45^{\prime}$ & $40^{\circ} 26^{\prime}$ & $41^{\circ} 47^{\prime}$ \\
\hline Orientación & NE & NW & NE \\
\hline Altitud (m s.n.m.) & 1230 & 1303 & 375 \\
\hline Altura $(\mathrm{m})$ & $24.0 \pm 0.5$ & $8.5 \pm 0.3$ & $7.8 \pm 0.3$ \\
\hline Edad a $1.3 \mathrm{~m}$ (años) & $85 \pm 3$ & $138 \pm 6$ & $104 \pm 4$ \\
\hline Frondosidad (\%) & $59.9 \pm 5.9$ & $58.0 \pm 4.9$ & $55.4 \pm 4.7$ \\
\hline Área de albura (\%) & $15.2 \pm 2.2$ & $8.6 \pm 1.2$ & $17.0 \pm 2.8$ \\
\hline Árboles totalmente defoliados (\%) & 21 & 5 & 10 \\
\hline Estación climática (distancia al sitio de estudio en km) & Jaca $(30)$ & Teruel $(15)$ & Zaragoza (24) \\
\hline
\end{tabular}
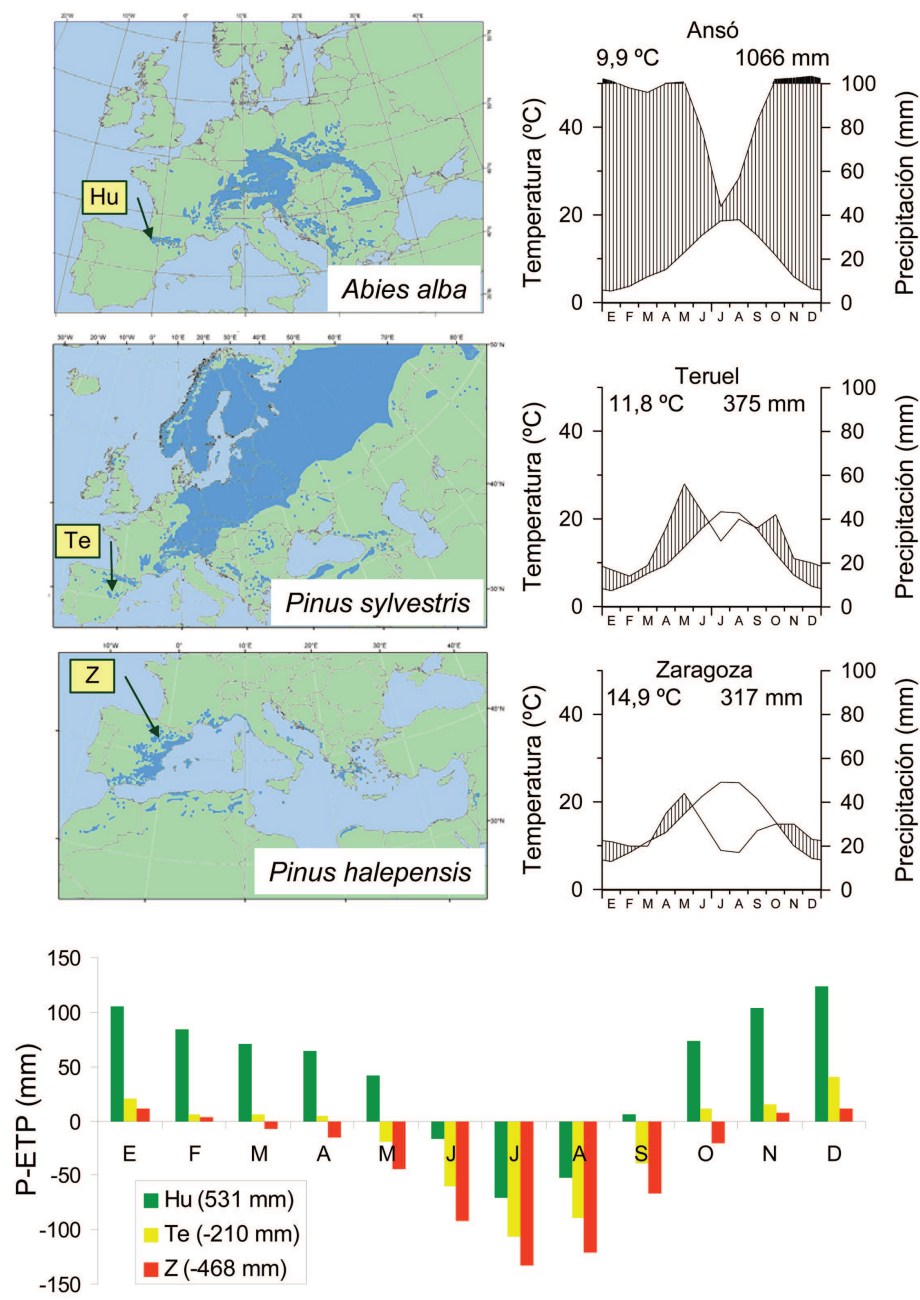

Figura 2. Contexto biogeográfico y climático de los bosques estudiados (ver características y códigos en la Tabla 1) respecto al área de distribución de cada especie en Europa (mapas extraídos de http://www.euforgen.org/distribution_maps.html) y considerando las condiciones climáticas de cada sitio (datos medios anuales, diagramas climáticos a la derecha, balance hídrico -diferencia entre la precipitación, P; y la evapotranspiración potencial, ETP-abajo). En el caso del abetar se muestran datos de la estación próxima de Ansó (situada a $1 \mathrm{~km}$ ) que no se usó para el análisis de datos climáticos por carecer de datos actualizados. tado Dendrocronología). El primer autor estimó el porcentaje de copa de cada árbol con ramas sosteniendo acículas verdes tomando como referencia un árbol con frondosidad máxima para cada especie y en cada sitio de estudio, dado que las estimas de frondosidad, o de su inversa la defoliación, varían entre observadores y zonas. La abundancia de muérdago la estimó el segundo autor usando una escala visual semi-cuantitativa que divide la copa en tres porciones iguales, asigna valores de 0 (ausencia de muérdago) a 2 (infestación máxima) a cada tercio y, consecuentemente, oscila a nivel de árbol entre 0 y 6 (Sangüesa-Barreda et al. 2012). En el caso del bosque de pino albar no observamos ninguna mata de muérdago pero sí muchos árboles con abundantes ramillas con acículas secas o rojizas recientes (casi todas del año 2011) por lo que estimamos su cobertura $(\%)$ respecto al total de la copa. Finalmente, anotamos observaciones que pudieran estar relacionadas con el vigor de cada árbol (presencia de hiedra en los abetos, presencia de escolítidos en los pinos).

Para comparar el estado de los árboles antes y después del periodo de mayor intensidad de la sequía (el balance hídrico suele ser mínimo en julio, ver Fig. 2) se realizaron dos muestreos en primavera (marzo) y verano (agosto) del 2012. En concreto, recogimos acículas de 1 año de edad formadas en 2011 o 2012 en marzo y agosto, respectivamente. En las mismas fechas tomamos muestras de albura del tronco que fueron conservadas en sobres humedecidos y sellados para evitar la pérdida de agua.

\section{Dendrocronología}

Para caracterizar el crecimiento radial durante la vida de cada árbol usamos métodos dendrocronológicos (Fritts 2001). A finales del verano del 2012, cuando casi todo el anillo de crecimiento ya estaba formado, extrajimos un testigo radial de madera del tronco principal de cada árbol a $1.3 \mathrm{~m}$ de altura usando una barrena de Pressler. Se consideró que un solo testigo radial era representativo del crecimiento del árbol dada la escasa madera de reacción y la escasa excentricidad de los anillos en la mayoría de los árboles muestreados (Woodall 2008). Medimos la anchura radial de albura en fresco en el campo ya que se distinguía con claridad en ambas especies de pinos y con cierta dificultad en el caso del abeto. En este último caso usamos una tinción de verde de bromocresol sobre la madera para comprobar las estimas visuales de albura (Kutscha y Sachs 1962). Este dato se transformó en porcentaje del área del xilema ocupada por la albura asumiendo que el tronco era circular. Los testigos de madera fueron secados y pulidos con lijas 
de grano sucesivamente más fino hasta distinguir los anillos anuales de crecimiento que se dataron visualmente (Yamaguchi 1991). Los anillos de crecimiento fueron medidos con una resolución de hasta $0.01 \mathrm{~mm}$ utilizando un sistema semiautomático de medición LINTAB (Rinn, Alemania). La datación de los anillos se evaluó posteriormente usando el programa COFECHA (Holmes 1983). Los datos de anchura del anillo se convirtieron en incremento de área basimétrica (IAB) usando la siguiente fórmula y asumiendo la circularidad de los troncos a $1.3 \mathrm{~m}$ :

$$
\mathrm{IAB}=\pi\left(r_{t}^{2}-r^{2} t-1\right)
$$

donde $r$ es el radio del árbol y $t$ es el año de formación del anillo de crecimiento. En el caso de testigos sin médula se estimó el centro teórico del árbol mediante un método geométrico que también se usó para estimar la edad a $1.3 \mathrm{~m}$ de altura. En todos los casos en los que se estimó el IAB se eliminó el efecto del espesor de la corteza que fue medido en el punto donde se extrajo el testigo. Se calcularon los valores medios de IAB y su autocorrelación de primer orden (calculada con un desfase de 1 año), que mide la similitud de IAB entre los años $t$ y $t$-1, para el periodo común 1950-2012. Se compararon los valores individuales de IAB entre árboles de la misma especie pero con niveles de frondosidad de dos clases: inferiores o superiores al $50 \%$ de la copa.

\section{Datos climáticos}

Se usaron datos climatológicos mensuales (temperaturas medias de las máximas y mínimas, precipitación total) para el periodo comprendido entre enero de 1950 y septiembre de 2012 procedentes de las siguientes estaciones meteorológicas: Jaca ( $42^{\circ} 34^{\prime} 14^{\prime \prime}$ $\mathrm{N}, 0^{\circ} 32^{\prime} 58^{\prime \prime} \mathrm{O}, 818 \mathrm{~m}$ s.n.m.), Teruel (402 $21^{\prime} 2^{\prime \prime} \mathrm{N}, 1^{\circ} 7^{\prime} 27^{\prime \prime} \mathrm{O}$, $900 \mathrm{~m})$ y Zaragoza-Aeropuerto $\left(41^{\circ} 39^{\prime} 38^{\prime \prime} \mathrm{N}, 1^{\circ} 0^{\prime} 15^{\prime \prime} \mathrm{O}, 263 \mathrm{~m}\right)$ (Tabla 1). Utilizando estos datos se calculó la evapotranspiración potencial y el balance hídrico mensual (diferencia entre precipitación y evapotranspiración) usando el método de Hargreaves basado en variables térmicas (medias mensuales de las temperaturas máximas y mínimas) y en datos de radiación solar estimada (Hargreaves y Samani 1985). Como paso previo al cálculo del índice de sequía, obtuvimos el balance hídrico acumulado para los tres sitios de estudio, considerando años hidrológicos desde octubre hasta septiembre.

Para reflejar e integrar los componentes térmicos y pluviométricos utilizamos el Índice de precipitación-evapotranspiración estandarizado (SPEI de sus siglas en inglés "Standardised precipitation-evapotranspiration index"; Vicente-Serrano et al. 2010). EI SPEI es un índice estandarizado y mutiescalar ya que se calcula para distintas escalas temporales considerando valores del balance hídrico durante el año juliano. EI SPEI permite así cuantificar la duración e intensidad de las sequías con valores negativos (positivos) que indican condiciones secas (húmedas). El SPEI es uno de los índices de sequía que mejor recoge el efecto del aumento de temperaturas sobre la evapotranspiración así como sus efectos sobre sistemas ecológicos (Vicente-Serrano et al. 2012). Basándonos en un estudio previo en el que se relacionó crecimiento radial de diversas especies de árboles con la intensidad y duración de la sequía evaluada mediante el SPEI (Pasho et al. 2011), calculamos dicho índice considerando sólo tres meses (junio, julio, agosto) cuando la tasa de crecimiento de las tres especies estudiadas suele ser elevada. Además, consideramos solamente aquellas escalas temporales en las que según Pasho et al. (2011) el crecimiento radial responde más al SPEI, que fueron de 2 a 5 meses en el caso de $A$. alba y $P$. sylvestris (correspondiendo a sequías breves) y de 12 a 15 meses en el caso de $P$. halepensis (correspondiendo a sequías de larga duración).

\section{Análisis químicos}

Se midieron las concentraciones de nitrógeno y las de carbohidratos no estructurales (CNEs) en acículas recientes recogidas en marzo (acículas formadas en 2011) o agosto (acículas formadas en 2012) y sólo CNEs en la albura del xilema del tronco principal del árbol (seleccionando los $5 \mathrm{~cm}$ más externos donde la concentración de CNEs es más o menos estable; Hoch et al. 2003). Las fechas de muestreo corresponden a los periodos previo (marzo, anterior a la sequía estival) y posterior (agosto, hacia el final de la sequía estival) a la brotación cuando las concentraciones de CNEs en acículas de 1 año suelen ser elevadas y bajas, respectivamente (Fischer y Höll 1991). Los análisis de carbohidratos se realizaron sobre muestras recogidas en el campo e inmediatamente mantenidas en una nevera portátil para su posterior procesado mediante congelación a $-20^{\circ} \mathrm{C}$ y liofilización. Las concentraciones de nitrógeno se obtuvieron usando un analizador automático Elementar VarioMAX (Hanau, Alemania). Los azúcares solubles se extrajeron usando una disolución de etanol al $80 \%$ y su concentración se determinó mediante un método colorimétrico utilizando el método del fenol-sulfúrico de Dubois et al. (1956) modificado por Buysse y Merckx (1993). El almidón y los azúcares complejos que permanecían sin disolver en el resto de la muestra después de las extracciones con etanol se redujeron enzimáticamente a glucosa y se analizaron según Palacio et al. (2007). Los CNEs medidos tras la extracción de etanol corresponden a azúcares solubles y aquellos medidos tras la digestión enzimática se expresan como almidón. La suma de azúcares solubles y almidón correspondería a la concentración total de CNEs.

\section{Análisis estadísticos}

Exploramos las relaciones entre la frondosidad de la copa, como variable que resume el vigor del árbol, respecto a otras variables referidas al tamaño (diámetro a $1.3 \mathrm{~m}$; altura), edad (número de anillos contados a $1.3 \mathrm{~m}$ ) y el vigor (abundancia de muérdago, cobertura de acículas secas) de los árboles. Además, relacionamos las concentraciones de nitrógeno en acículas y de CNEs en la albura antes y después de la sequía estival para determinar si existía persistencia temporal en dichas variables. Para los análisis citados calculamos correlaciones usando el índice no paramétrico de Spearman $\left(r_{s}\right)$ y corregimos su nivel asociado de probabilidad por el posible efecto de la presencia de autocorrelación espacial siguiendo el método de Dutilleul (1993).

\section{Resultados}

\section{Contexto temporal de la sequía del año 2012}

En las tres estaciones climatológicas analizadas, el balance hídrico acumulado alcanzó valores mínimos para el periodo considerado (1950-2012) en el año hidrológico 2011-2012 excepto en Teruel donde se alcanzaron valores menores en 1981-1982 y 19841985 (Figs. 3 y 4). Según dicho balance el déficit hídrico estimado para septiembre del 2012 fue en todos los casos similar o inferior al valor medio del periodo 1950-2012 menos 2.5 veces la desviación estándar. Según el índice de sequía SPEI en los bosques de abeto y pino carrasco la intensidad de la sequía, calculada a escalas temporales breves (2-5 meses) y largas (12-15 meses), alcanzó valores récord de intensidad para el periodo analizado (1950-2012) (Fig. 4). La severidad de la sequía del 2012 corresponde en gran medida al aumento de las temperaturas primaverales y estivales, patente desde aproximadamente 1980 y muy manifiesto en la década pasada. Por el contrario, las precipitaciones no mostraron tendencias a largo plazo (resultados no mostrados) aunque sí han sido puntualmente bajas en ciertos periodos (p. ej. 1965, 1985-1986, 1994-1995, 2005).

\section{Tamaño, edad, vigor y crecimiento}

La única especie en la que la frondosidad estaba relacionada de forma positiva con la edad del árbol fue $P$. halepensis (Tabla 2). Sólo la anchura de albura estaba relacionada positiva y significativamente con la frondosidad de la copa en las tres especies estudiadas (Tabla 2), manteniéndose dicha relación al usar área de albura en el caso de $A$. alba. En $P$. sylvestris, el porcentaje de ra- 


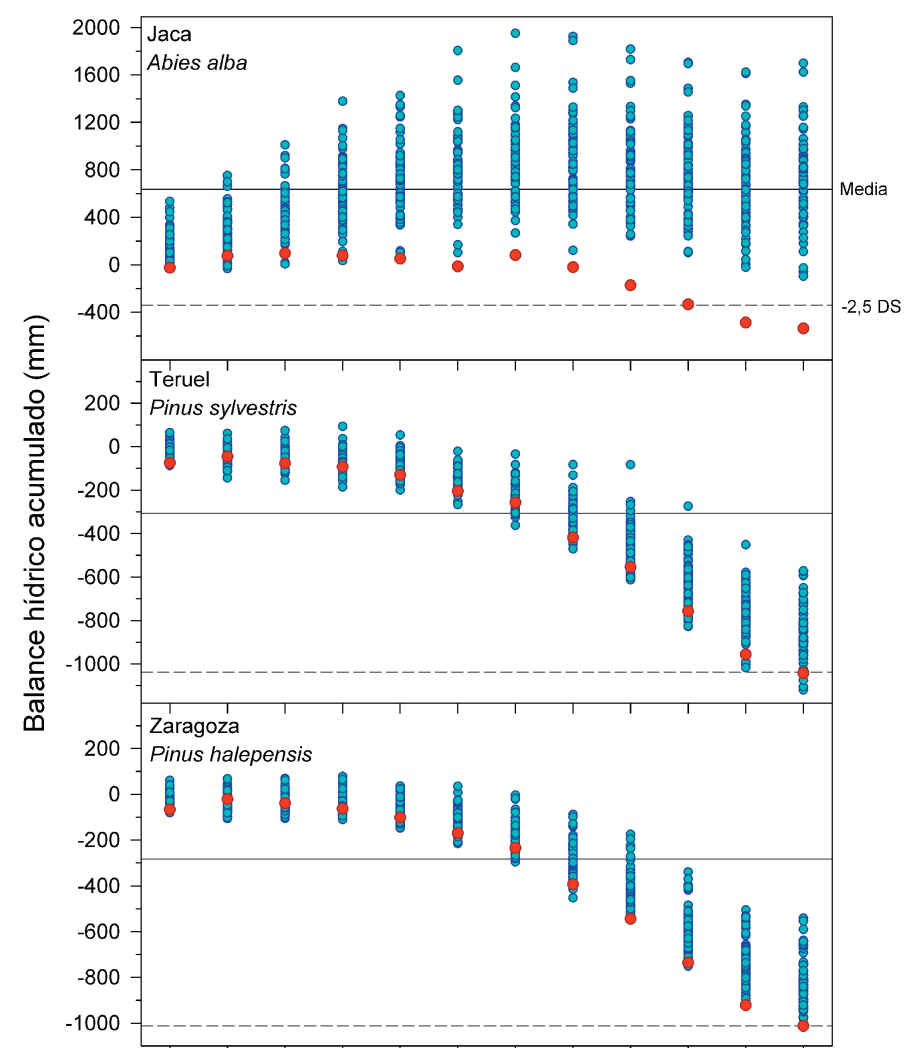

Oct Nov Dic Ene Feb Mar Abr May Jun Jul Ago Sep

Meses

Figura 3. En el año 2012 la intensidad de la sequía fue muy acentuada durante la época de crecimiento tal y como muestra el balance hídrico acumulado (suma de las diferencias entre la precipitación y la evapotranspiración potencial mensuales) para los tres sitios y especies de estudio considerando años hidrológicos (octubre-septiembre) durante el periodo 1950-2012. Los símbolos rojos corresponden al año hidrológico 2011-2012 y las líneas horizontales continua y discontinua indican el valor medio del periodo y la media menos 2,5 veces la desviación estándar, respectivamente.

Tabla 2. Correlaciones entre la frondosidad de la copa y diversas variables de tamaño y vigor para las tres especies estudiadas ( $n=38$ árboles por especie). Entre paréntesis se muestra el nivel de probabilidad y en negrita se indican las correlaciones significativas $(p<0.05)$.

\begin{tabular}{ccccccc}
\hline Especie & $\begin{array}{c}\text { Diámetro } \\
\mathbf{a} \mathbf{1 . 3} \mathbf{~ m}\end{array}$ & Altura & $\begin{array}{c}\text { Edad } \\
\text { a } \mathbf{1 . 3} \mathbf{~ m}\end{array}$ & Muérdago & $\begin{array}{c}\text { Longitud } \\
\text { de albura }\end{array}$ & $\begin{array}{c}\text { Área } \\
\text { de albura }\end{array}$ \\
\hline \multirow{2}{*}{ A. alba } & 0.21 & 0.08 & -0.02 & -0.28 & $\mathbf{0 . 7 1}$ & $\mathbf{0 . 6 0}$ \\
& $(0.55)$ & $(0.64)$ & $(0.92)$ & $(0.87)$ & $(0.001)$ & $(0.001)$ \\
P. sylvestris & 0.12 & 0.16 & -0.26 & & $\mathbf{0 . 2 8}$ & 0.10 \\
& $(0.37)$ & $(0.31)$ & $(0.12)$ & -- & $(0.05)$ & $(0.25)$ \\
P. halepensis & 0.15 & -0.08 & $\mathbf{0 . 4 3}$ & -0.09 & $\mathbf{0 . 4 0}$ & 0.13 \\
& $(0.22)$ & $(0.69)$ & $(0.01)$ & $(0.90)$ & $(0.009)$ & $(0.52)$ \\
\hline
\end{tabular}

millas con acículas secas o rojizas recientes estaba relacionado negativamente con la frondosidad de la copa $\left(r_{s}=-0.74, p=0.001\right)$. La frondosidad también mostró relaciones significativas $(p<0.001)$ pero negativas con el contenido relativo de materia seca de la albura muestreada en primavera en $A$. alba $\left(r_{s}=-0.72\right)$ y $P$. halepen$\operatorname{sis}\left(r_{s}=-0.68\right)$. Dichas relaciones entre frondosidad y contenido de materia seca se mantuvieron en verano aunque fueron menos fuertes que en primavera (resultados no mostrados).

En relación al crecimiento la frondosidad estaba relacionada con el año de formación del anillo de crecimiento más reciente. Esta relación destacaba en $P$. halepensis ya que en esta especie algunos árboles con frondosidad inferior al 50\% mostraban su anillo más reciente 12 años antes del muestreo mientras que en el resto de especies dichos árboles defoliados dejaron de crecer 4 o 5 años antes (Fig. 5). Las curvas medias de IAB muestran decli-

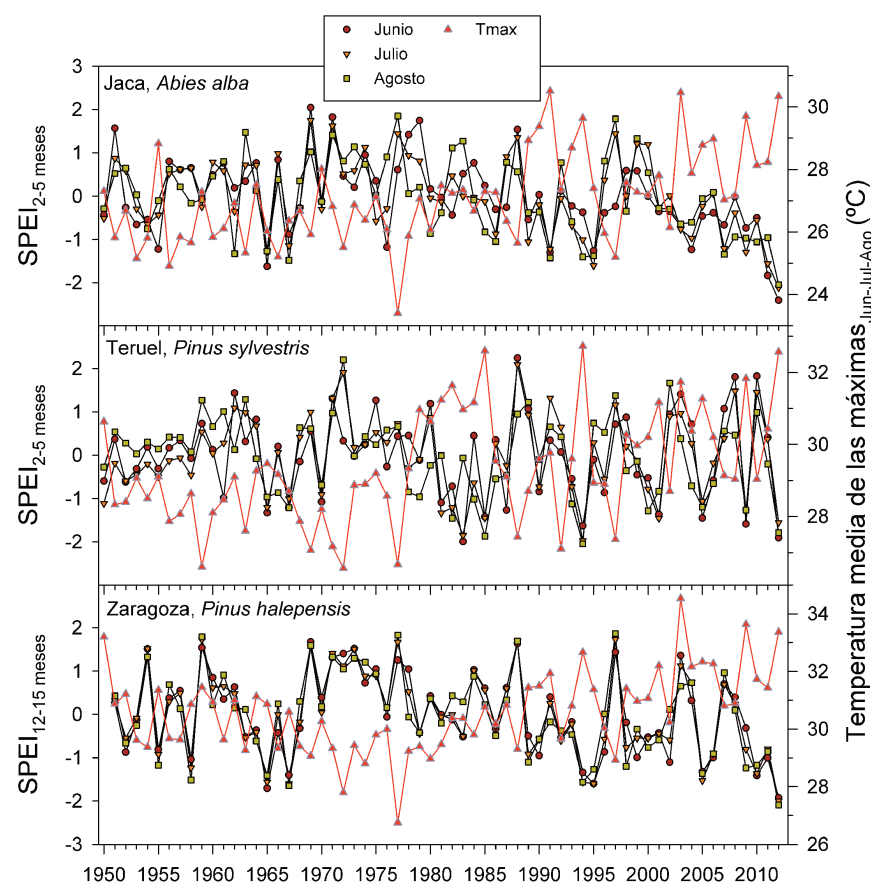

Años

Figura 4. La sequía de la primavera y verano del año 2012 y las elevadas temperaturas carecen de precedentes similares desde 1950. Intensidad de la sequía para los meses de junio, julio y agosto en relación al aumento de las temperaturas medias de las máximas de dichos meses para el periodo 1950-2012 en observatorios representativos de los sitios estudiados (Jaca, A. alba; Teruel, P. sylvestris; Zaragoza, P. halepensis). Nótese la intensidad de la sequía del año 2012 en los observatorios de Jaca $\left(S P E I_{j u n i o}=-2.4\right)$ y Zaragoza ( $\left.S P E I_{\text {agosto }}=-2.1\right)$. La intensidad y duración de la sequía se caracterizó usando el índice SPEI ("Standardised precipitation-evapotranspiration index") calculado para escalas cortas de 2-5 meses -sequías breves(A. alba, P. sylvestris) o de 12-15 meses -sequías largas- (P. halepensis).

ves de crecimiento que se remontan hasta el año 2000 aproximadamente en $A$. alba y $P$. halepensis o bien corresponden a caídas bruscas anuales (p. ej. 2005) en el caso de P. sylvestris (Fig. 6). Los árboles con frondosidad inferior al $50 \%$ y sin crecimiento secundario reciente, un indicador de muerte potencial, muestran patrones diversos de IAB respecto a los árboles frondosos. Tanto en $A$. alba como en $P$. halepensis los árboles con frondosidad inferior al $50 \%$ de la copa presentaron un elevado crecimiento secundario en periodos climáticamente benignos (1970-1974) mientras que los árboles de $P$. sylvestris poco frondosos siempre han mostrado valores bajos de IAB (Fig. 7).

La frondosidad de la copa no mostró relaciones importantes con el crecimiento medio del árbol excepto en el caso de $P$. sylvestris $\left(r_{s}=0.30, p=0.07\right)$. Sin embargo, detectamos una relación negativa entre frondosidad y autocorrelación temporal de primer orden del IAB $\left(A\right.$. alba, $r_{s}=-0.51, p=0.001 ; P$. sylvestris, $r_{s}=-0,44, p=$ 0.007 ; $P$. halepensis, $\left.r_{s}=-0.34, p=0.05\right)$. Además, la frondosidad estaba relacionada positivamente con la correlación de la serie de crecimiento individual de cada árbol con la serie media de todos los árboles en $P$. sylvestris $\left(r_{s}=0.48 ; p=0.003\right)$.

\section{Nitrógeno y carbohidratos no estructurales}

Sólo detectamos relaciones significativas entre las concentraciones de nitrógeno y de CNEs en el caso de las acículas formadas en 2011 y 2012 por $P$. sylvestris, ya se tratara de las muestreadas en primavera $\left(r_{s}=0.54 ; p=0.002\right)$ o en verano $\left(r_{s}=0.42 ; p=0.02\right)$. Respecto a posibles cambios de las variables químicas de la albura en primavera y verano todas las variables consideradas estaban significativamente correlacionadas entre ambos muestreos estacionales excepto en el caso de las concentraciones de almidón en A. alba $\left(r_{s}=0.18 ; p=0.17\right)$ y de azúcares solubles en $P$. sylvestris $\left(r_{s}=0.27 ; p=0.10\right)$. 


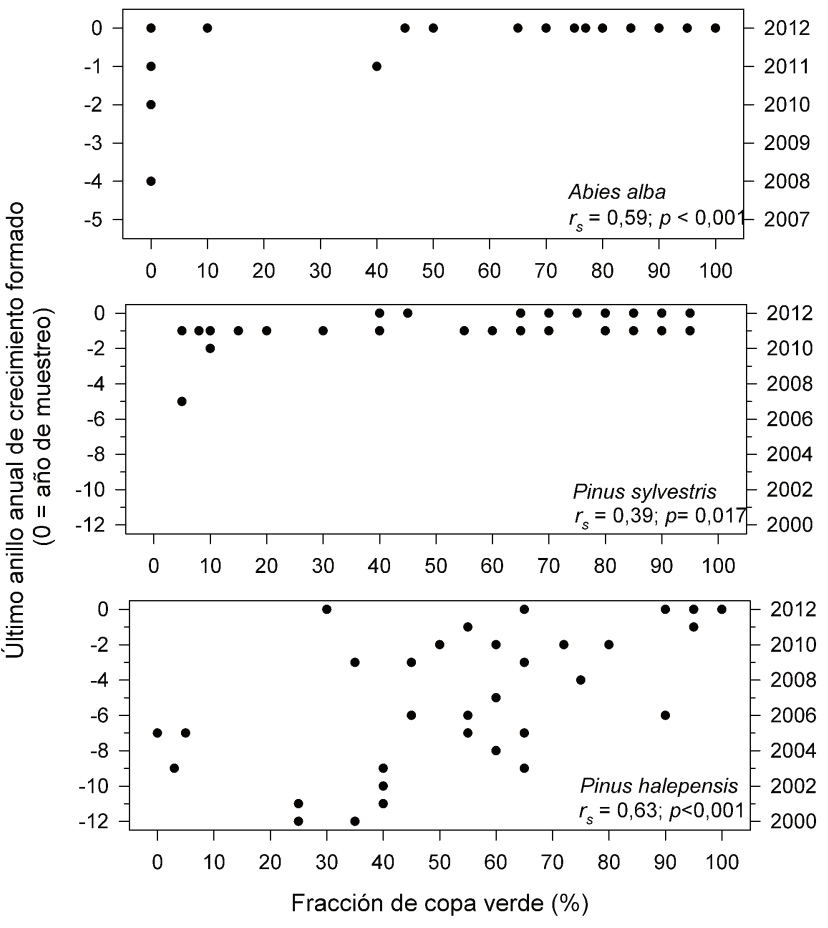

Figura 5. La defoliación de la copa expresaba la pérdida o el cese de crecimiento radial ya que la fracción de copa verde (frondosidad) estaba relacionada con el año de formación del anillo de crecimiento más reciente. Esta relación fue especialmente importante en P. halepensis.

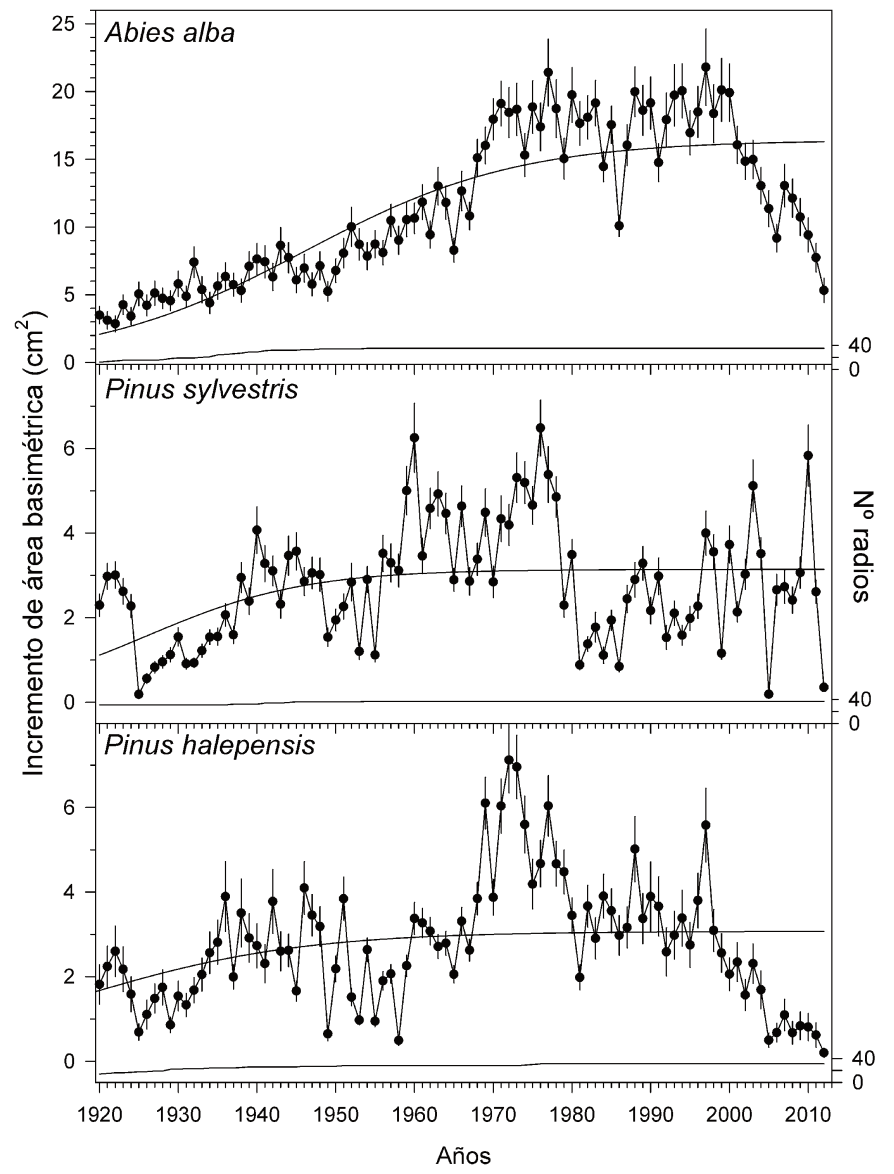

Figura 6. Las tendencias a largo plazo del incremento de área basimétrica corresponden a declives de crecimiento que pueden durar una década (A. alba, P. halepensis) o son más puntuales (P. sylvestris). Se muestran los valores medios del incremento de área basimétrica de todos los árboles muestreados y un ajuste logístico sencillo a esta curva media. Las líneas inferiores indican el número de árboles medidos cada año (eje derecho de ordenadas). Las barras de error corresponden al error estándar.

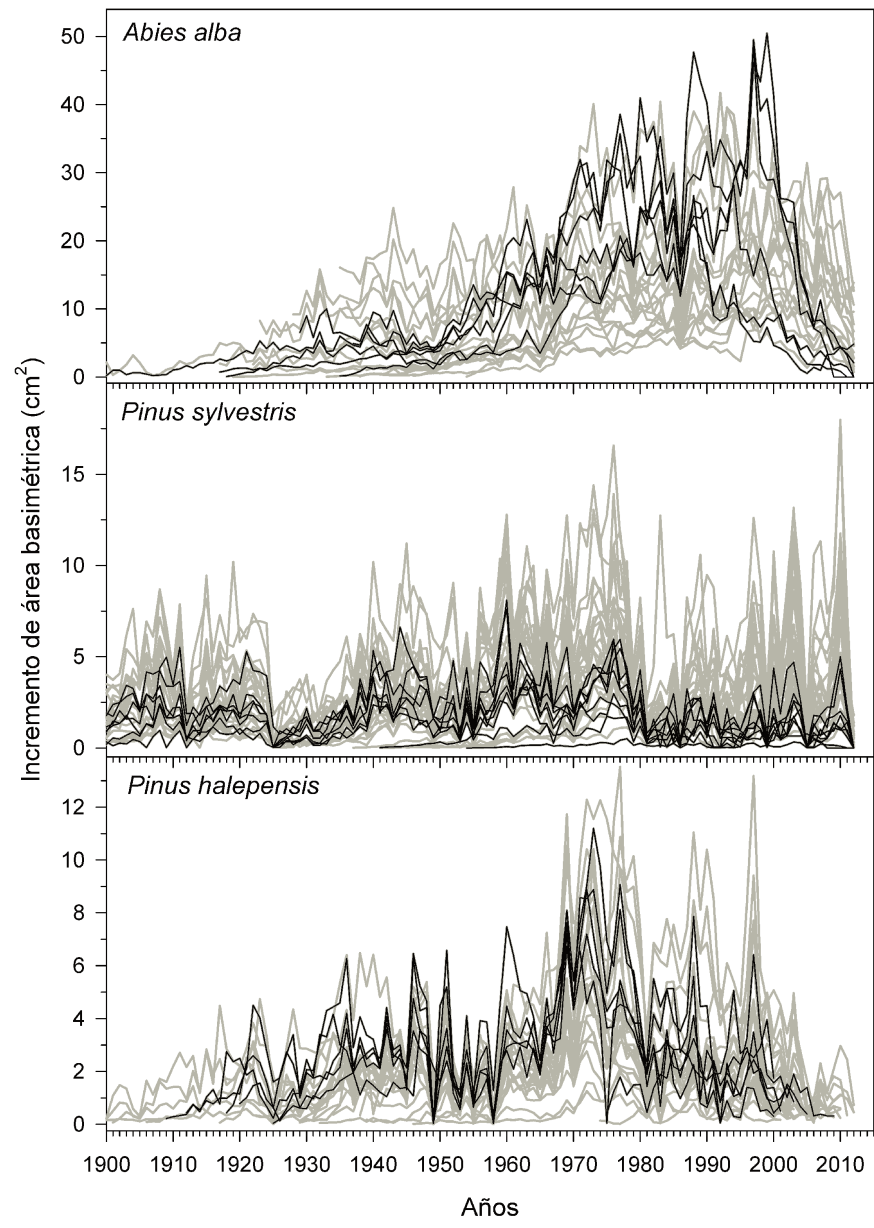

Figura 7. Los árboles muy defoliados (frondosidad inferior al 50\%) muestran patrones diversos de crecimiento en cada especie. Se muestran las curvas individuales de incremento de área basimétrica para árboles con frondosidad de la copa inferior (líneas negras) o superior (líneas grises) al $50 \%$. Sólo se representaron los árboles con frondosidad inferior al $50 \%$ y sin crecimiento en el año de muestreo, lo que podría indicar un proceso de mortalidad incipiente.

Observamos que la frondosidad de la copa estaba relacionada de manera positiva y significativa con la concentración de CNEs en la albura, particularmente en el caso de los azúcares solubles (Fig. 8). Esta relación se encontraba para la albura muestreada en primavera o en verano en el caso de $P$. halepensis y de $A$. alba, pero dicha relación no fue significativa en las muestras primaverales de P. sylvestris (Tabla 3, Fig. 8). Sin embargo, no encontramos ninguna relación significativa entre la frondosidad de copa, ni tampoco considerando el porcentaje de ramillas secas en el caso de $P$. sylvestris, respecto a las variables químicas medidas en las acículas y sólo cabe reseñar una relación negativa entre la frondosidad y la concentración de azúcares solubles en las acículas del 2011 en $P$. sylvestris $\left(r_{s}=-0.26 ; p=0.10\right)$.

\section{Discusión}

Los datos presentados muestran procesos diversos de decaimiento en las tres especies comparadas y algún patrón común. La sequía extrema del año 2012 contribuyó al descenso de la frondosidad y al cese del crecimiento secundario en muchos de los individuos estudiados. Estos cambios aparecieron vinculados con la progresiva producción de menos albura y posiblemente dicha albura mostró un menor grado de hidratación.

En relación con nuestra hipótesis inicial, los datos de crecimiento secundario indican que el proceso de decaimiento podría ser reciente aunque progresivo y remontarse al menos 10 años antes en $A$. alba y $P$. halepensis, las dos especies en las que los individuos menos frondosos en la actualidad respondieron en el pasado más vigorosamente a condiciones climáticas benignas en 


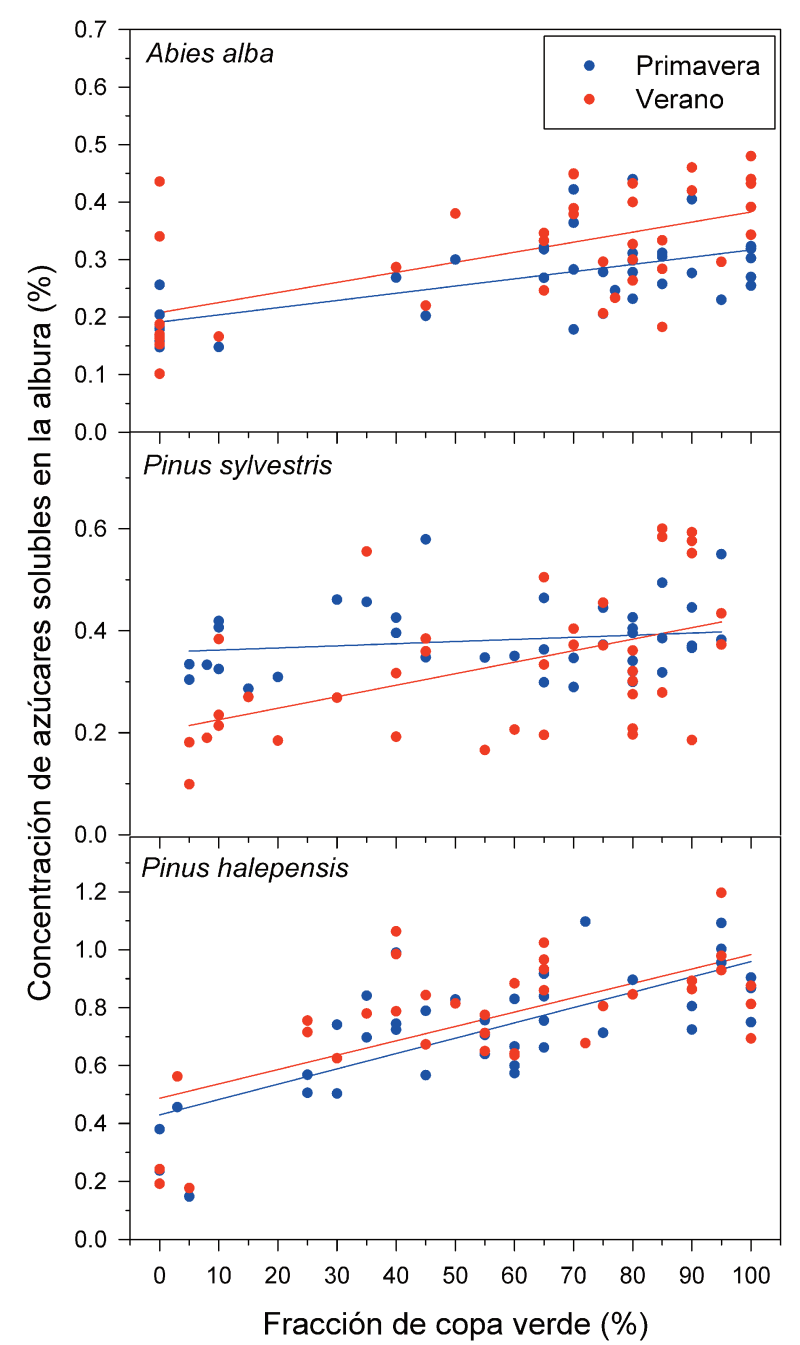

Figura 8. La frondosidad de la copa refleja la concentración de azúcares solubles de la albura del tronco. Se muestran las relaciones entre frondosidad (fracción de copa verde) y concentración de azúcares solubles de la albura medida en primavera (símbolos y líneas azules) o verano (símbolos y líneas rojos). Los ajustes lineales se muestran a modo orientativo.

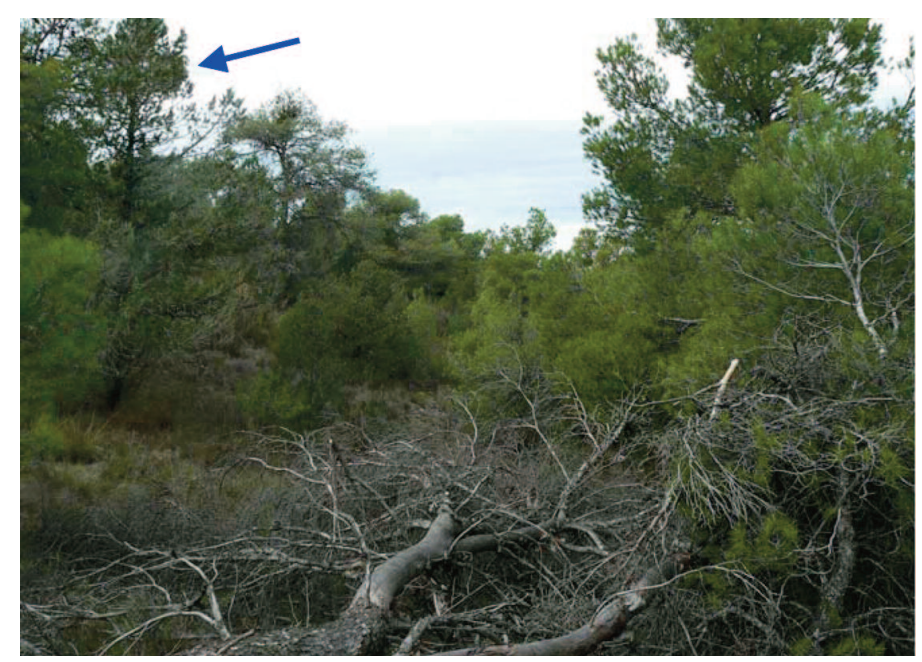

Figura 9. La mortalidad selectiva de las especies de árboles más vulnerables frente a la sequía está favoreciendo su sustitución por otras más resistentes lo que puede anunciar cambios futuros en la composición de los bosques. Por ejemplo, en el Vedado de Peñaflor la mortalidad de pino carrasco (Pinus halepensis) podría favorecer su reemplazamiento en algunas zonas por sabina albar (Juniperus thurifera; flecha azul) que hasta hoy formaba una población relicta de pocos individuos. Un proceso similar de sustitución de la especie dominante inducida por la sequía se observa en la población en declive de pino albar estudiada cerca de Teruel donde el pino laricio (P. nigra subsp. salzmannii) coexiste con el pino albar.

\begin{tabular}{cccccccc}
\hline \multicolumn{3}{c}{ Primavera } & \multicolumn{3}{c}{ Verano } \\
\hline Especie & $\begin{array}{c}\text { Azúcares } \\
\text { solubles }\end{array}$ & Almidón & $\begin{array}{c}\text { Azúcares } \\
\text { totales }\end{array}$ & $\begin{array}{c}\text { Azúcares } \\
\text { solubles }\end{array}$ & Almidón & $\begin{array}{c}\text { Azúcares } \\
\text { totales }\end{array}$ \\
\hline \multirow{2}{*}{ A. alba } & $\mathbf{0 . 4 0}$ & $\mathbf{0 . 4 1}$ & $\mathbf{0 . 4 5}$ & $\mathbf{0 . 5 3}$ & $\mathbf{0 . 3 3}$ & 0.54 \\
& $(0.007)$ & $(0.006)$ & $(0.002)$ & $(<0.001)$ & $(0.05)$ & $(<0.001)$ \\
P. sylvestris & 0.21 & 0.04 & 0.07 & $\mathbf{0 . 5 1}$ & 0.05 & 0.24 \\
& $(0.24)$ & $(0.73)$ & $(0.50)$ & $(<0.001)$ & $(0.75)$ & $0.14)$ \\
P. halepensis & $\mathbf{0 . 6 4}$ & $\mathbf{0 . 4 9}$ & $\mathbf{0 . 6 0}$ & $\mathbf{0 . 5 4}$ & $\mathbf{0 . 4 0}$ & $\mathbf{0 . 6 1}$ \\
& $(<0.001)$ & $(0.02)$ & $(<0.001)$ & $(<0.001)$ & $(0.02)$ & $(0.001)$ \\
\hline
\end{tabular}

Tabla 3. Correlaciones entre la frondosidad de la copa y las concentraciones de carbohidratos no estructurales en la albura del tronco muestreada en primavera y verano para las tres especies estudiadas. El resto de comentarios son como en la Tabla 2.

cuanto a producción de madera. Sin embargo, los individuos defoliados de $P$. halepensis han sido capaces de sobrevivir en condiciones semiáridas sin formar anillos de crecimiento mientras que en el caso del abetar bajo condiciones mucho más húmedas la mayoría de los árboles sin crecimiento secundario podrían considerarse muertos desde el punto de vista de la xilogénesis. Esta diferencia indica la dificultad de usar la ausencia de crecimiento radial como indicador de muerte en el caso del pino carrasco y en otras especies leñosas sometidas a niveles de déficit hídrico elevados y posiblemente adaptadas a este estrés climático (Wilmking et al. 2012). Por el contrario, dicha distinción sugiere la utilidad de variables relacionadas con la baja actividad del cámbium, como el cese de producción de anillos, para definir la muerte del árbol en el caso del abeto y en otras especies o poblaciones de árboles no sometidas a niveles muy elevados de déficit hídrico. Por otro lado, la pérdida de frondosidad parece tener un componente ontogenético en el caso de la población de $P$. halepensis mientras que en las otras especies edad y defoliación no están relacionadas. En $P$. sylvestris, el decaimiento podría calificarse como más "puntual" en respuesta a sequías extremas aunque más prolongado en el tiempo ya que los individuos en decaimiento muestran menores tasas de crecimiento que los de mejor vigor durante casi todo el siglo pasado, lo que explicaría la relación negativa entre frondosidad y crecimiento medio. Estos patrones de crecimiento contrastados entre especies sugerirían procesos de decaimiento controlados por factores climáticos de estrés diferentes (compárense las Fig. 4 y 6), más vinculados al aumento de las temperaturas (p. ej. A. alba), $\mathrm{o}$ a interacciones entre dicho calentamiento y periodos escalonados de sequía acentuada (p. ej. $P$. halepensis) o a episodios recurrentes de sequías extremas (p. ej. $P$. sylvestris).

En este sentido es reseñable la ausencia de relaciones entre la frondosidad y la concentración de CNEs en las hojas jóvenes, donde se acumulan la mayor parte de las reservas móviles de carbono. Este resultado concuerda con el hecho de que las coníferas perennifolias sean capaces de restaurar rápidamente sus reservas de CNEs tras defoliaciones intensas (Li et al. 2002). Por tanto, nuestros datos no apoyan un agotamiento de reservas de carbono a corto plazo como consecuencia de la sequía o de la defoliación tal y como otros autores han evidenciado en $P$. sylvestris (Gruber et al. 2012). No obstante, las relaciones positivas entre la frondosidad de la copa y la concentración de azúcares solubles en la albura, que es un reservorio minoritario en cuanto a contenido total de CNEs en comparación con las acículas jóvenes, sí podrían apuntar hacia una disminución a medio plazo de las reservas de carbono depositadas en el xilema del tronco como consecuencia de la defoliación y en relación al descenso de crecimiento radial (Galiano et al. 2011). No obstante, no pueden descartarse otras explicaciones como la movilización de estos azúcares para ser usados como osmolitos en respuesta a la sequía o bien ser consumidos en la respiración.

Nuestros datos sugieren por lo tanto respuestas funcionales a corto, medio y largo plazo lo que podría explicar que los árboles más defoliados tiendan a presentar mayor persistencia temporal en su crecimiento y menor concentración de azúcares solubles en la albura. Desconocemos hasta qué punto están relacionadas ambos 
patrones en los procesos de decaimiento ya que, por lo que sabemos, no habían sido descritos hasta la fecha. En Fagus sylvatica se ha descrito un mayor descenso de CNEs en la albura de árboles en decaimiento que en aquella de individuos vigorosos lo que sugiere que las reservas de carbono podrían agotarse en la albura más interna de árboles más decaídos (Gérard y Bréda 2012). Esta sugerencia indicaría la necesidad de indicadores más fiables de la disponibilidad a largo plazo de carbono y de la capacidad de transferencia radial de CNEs. Aún no entendemos cómo las reservas de carbono móvil en la albura determinan la resiliencia y la respuesta post-decaimiento de los árboles durante episodios climáticamente desfavorables como las sequías que causan descensos de crecimiento claramente relacionados con la disponibilidad hídrica y promueven la pérdida acusada de follaje. Esperamos que nuestros resultados contribuyan al debate entre las hipótesis mecanicistas que explican el decaimiento basadas en las limitaciones por carbono. Proponemos centrar estudios futuros en el crecimiento secundario (ver Candel-Pérez et al. 2012) como indicador de la capacidad de recuperación a medio y largo plazo (resiliencia) tras decaimientos inducidos por sequía (Lloret et al. 2011, Lloret 2012). El estudio retrospectivo del crecimiento y vigor de los árboles debería complementarse con seguimientos que consideren su capacidad de recuperación a distintas escalas temporales. El año 2012 constituye un experimento natural ideal en el nordeste ibérico ya que las abundantes precipitaciones recogidas a partir de octubre en los tres bosques estudiados permitirán restaurar las reservas hídricas del suelo y examinar la capacidad de recuperación y rehidratación de los árboles. Este seguimiento debería completarse con estudios a nivel de comunidad que caractericen los cambios en la composición de estos bosques (Fig. 9). Se debería tratar de determinar si existirá un cambio en la comunidad, a qué escala espacial se producirá (rodal, bosque, paisaje) (Rigling et al. 2012) y si dicho cambio será excepcional dentro de la intensa modificación que están experimentando los bosques ibéricos como consecuencia de los cambios radicales en su uso y gestión de las últimas cinco décadas. Es evidente que los cambios de uso y gestión de los bosques condicionan en gran medida cómo éstos responderán a los cambios de clima (Linares et al. 2012; Sánchez-Salguero et al. 2012). En última instancia se trata de determinar hasta qué punto son las comunidades, las especies o los individuos vulnerables o no al cambio climático y dónde y cuáles lo son más o menos.

\section{Agradecimientos}

Agradecemos la revisión realizada por Luis Cayuela y por dos revisores anónimos de una versión previa del texto. Gran parte de este trabajo se inspira en diálogos mantenidos con Rodolfo Hernández Alonso (Laboratorio de Sanidad Forestal, Gobierno de Aragón, Mora de Rubielos, Teruel) a quien el primer autor agradece sus enseñanzas. Gracias a Elena Lahoz por realizar los análisis químicos. Este estudio se realizó mediante el apoyo de diversos proyectos financiados por el Plan Nacional de I+D+i (CGL201126654) o por el Organismo Autónomo de Parques Nacionales (387/2011). JJC agradece el apoyo de ARAID y la colaboración de la red Globimed (www.globimed.net). Agradecemos a la Agencia Estatal de Meteorología (AEMET) por facilitar los datos climáticos.

\section{Bibliografía}

Adams, H.D., Guardiola-Claramonte, M., Barron-Gafford, G.A., Villegas, J.C., Breshears, D.D., Zou, C.B., Troch, P.A., Huxman, T.E. 2009. Temperature sensitivity of drought-induced tree mortality portends increased regional die-off under global-change-type drought. Proceedings of the National Academy of Sciences of the USA 106:7063-7066.

Allen, C.D, Macalady, A.K., Chenchouni, H., Bachelet, D., McDowell, N., Vennetier, M., Kitzberger, T., Rigling, A., Breshears, D.D., Hogg, E.H., Gonzalez, P., Fensham, R., Zhang, Z., Castro, J., Demidova, N., Lim, J.H., Allard, G., Running, S.W., Semer, A., Cobb, N. 2010. A global overview of drought and heat-induced tree mortality reveals emerging climate change risks for forests. Forest Ecology and Management 259:660-684.
Anderegg, W.R.L., Berry, J.A., Field, C.B. 2012a. Linking definitions, mechanisms, and modeling of drought-induced tree death. Trends in Plant Science Doi.:10.1016/j.tplants.2012.09.006.

Anderegg, W.R.L., Kane, J.M., Anderegg, L.D.L. 2012b. Consequences of widespread tree mortality triggered by drought and temperature stress. Nature Climate Change Doi:10.1038/nclimate1635.

Bigler, C., Bräker, O.U., Bugmann, H., Dobbertin, M., Rigling, A. 2006. Drought as an inciting mortality factor in Scots pine stands of the Valais, Switzerland. Ecosystems 9:330-343.

Bonan, G.B. 2008. Forests and climate change: forcings, feedbacks, and the climate benefits of forests. Science 320:1444-1449.

Bréda, N., Huc, R., Granier, A., Dreyer, E. 2006. Temperate forest trees and stands under severe drought: a review of ecophysiological responses, adaptation processes and long-term consequences. Annals of Forest Science 63:625-644.

Breshears, D.D., Cobb, N.S., Rich, P.M., Price, K.P., Allen, C.D., Balice, R.G., Romme, W.H., Kastens, J.H., Floyd, M.L., Belnap, J., Anderson, J.J., Myers, O.B., Meyer, C.W. 2005. Regional vegetation die-off in response to global-change-type drought. Proceedings of the National Academy of Sciences of the USA 102:15144-15148.

Buysse, J., Merckx, R. 1993. An improved colorimetric method to quantify sugar content of plant tissue. Journal of Experimental Botany 44:16271629.

Candel-Pérez, D., Lucas-Borja, M.E., Linares, J.C. 2012. Predicciones del crecimiento en poblaciones de pino laricio (Pinus nigra Arn. ssp. salzmanii) bajo diferentes escenarios futuros de cambio climático. Ecosistemas 21(3):41-49.

Dobbertin, M. 2005. Tree growth as indicator of tree vitality and of tree reaction to environmental stress: a review. European Journal of Forest Research 124: 319-333.

Dubois, M., Gilles, K.A., Hamilton, J.K., Rebers, P.A., Smith, F. 1956. Colorimetric method for determination of sugars and related substances. Analytical Chemistry 28:350-356.

Dutilleul, P. 1993. Modifying the $t$ test for assessing the correlation between two spatial processes. Biometrics 49:305-314.

Fischer, C., Höll, W. 1991. Food reserves of Scots pine (Pinus sylvestris L.). 1. Seasonal-changes in the carbohydrate and fat reserves of pine needles. Trees 5:187-195.

Fritts, H.C. 2001. Tree rings and climate. Blackburn Press, Caldwell, NJ., USA.

Galiano, L., Martínez-Vilalta, J., Lloret, F. 2011. Carbon reserves and canopy defoliation determine the recovery of Scots pine $4 \mathrm{yr}$ after a drought episode. New Phytologist 190:750-759.

Gérard, B., Bréda, N. 2012. Radial distribution of carbohydrate reserves in the trunk of declining European beech trees (Fagus sylvatica L.). Annals of Forest Science Doi.:10.1007/s13595-012-0240-1

Gruber, A., Pirkebner, D., Florian, C., Oberhuber, W. 2012. No evidence for depletion of carbohydrate pools in Scots pine (Pinus sylvestris L.) under drought stress. Plant Biology 14:142-148.

Hargreaves, G.H., Samani, Z.A. 1985. Reference crop evapotranspiration from temperature. Transaction of ASAE 1:96-99.

Hoch, G., Richter, A,, Körner, Ch. 2003. Non-structural carbon compounds in temperate forest trees. Plant, Cell and Environment 26:1067-1081.

Holmes, R.L. 1983. Computer-assisted quality control in tree-dating and measurement. Tree-Ring Bulletin 43:69-78.

Kutscha, N.P., Sachs, I.B. 1962. Color tests for differentiating heartwood and sapwood in certain softwood tree species. USDA Forest Service, Report. No. 2246

Li, M.H., Hoch, G., Körner, C. 2002. Source/sink removal affects mobile carbohydrates in Pinus cembra at the Swiss treeline. Trees 16:331-337.

Linares, J.C., Camarero, J.J. 2012. From pattern to process: linking intrinsic water-use efficiency to drought-induced forest decline. Global Change Biology 18:1000-1015.

Linares, J.C., Pazo Sarria, R., Taïqui, L., Camarero, J.J., Ocho, V., Lechuga, V., Seco, J.I., Viñegla, B., Sangüesa, G., Gilarte, P., Merino, J., Carreira, J.A. 2012. Efectos de las tendencias climáticas y la degradación del hábitat sobre el decaimiento de los cedrales (Cedrus atlantica) del norte de Marruecos. Ecosistemas 21(3):7-14

Lloret, F. 2012. Vulnerabilidad y resiliencia de los ecosistemas terrestres frente a episodios extremos de sequía. Ecosistemas 21(3):85-89.

Lloret, F., Keeling, E.G., Sala, A. 2011. Components of tree resilience: effects of successive low-growth episodes in old ponderosa pine forests. Oikos 120:1909-1920.

Lloret, F., Escudero, A., Iriondo, J. M., Martínez-Vilalta, J., Valladares, F. 2012. Extreme climatic events and vegetation: the role of stabilizing processes. Global Change Biology 18:797-805. 
Martínez-Vilalta, J., Aguadé, D., Banqué, M., Barba, J., Curiel Yuste, J., Galiano, L., Garcia, N., Gómez, M., Hereş, A.M., López, B.C., Lloret, F., Poyatos, R. Retana, J. Sus, O., Vayreda, J., Vilà-Cabrera, A. 2012. Las poblaciones ibéricas de pino albar ante el cambio climático: con la muerte en los talones. Ecosistemas 21(3):15-21.

van Mantgem, P.J., Stephenson, N.L., Byrne, J.C., Daniels, L.D., Franklin, J.F., Fulé, P.Z., Harmon, M.E., Larson, A.J., Smith, J.M., Taylor, A.H., Veblen, T.T. 2009. Widespread increase of tree mortality rates in the western United States. Science 323:521-524.

McDowell, N.G. 2011. Mechanisms linking drought, hydraulics, carbon metabolism, and vegetation mortality. Plant Physiology 155:1051-1059.

Palacio, S., Maestro, M., Montserrat-Martí, G. 2007. Seasonal dynamics of non-structural carbohydrates in two species of Mediterranean subshrubs with different leaf phenology. Environmental and Experimental Botany 59:34-42.

Pasho, E., Camarero, J.J., de Luis, M., Vicente-Serrano, S.M. 2011. Impacts of drought at different time scales on forest growth across a wide climatic gradient in north-eastern Spain. Agricultural and Forest Meteorology 151:1800-1811.

Rigling, A., Bigler, C., Eilmann, B., Feldmeyer-Christe, E., Gimmi, U., Ginzler, C., Graf, U., Mayer, P., Vacchiano, G., Weber, P., Wohlgemuth, T. Zweifel, R., Dobbertin, M. 2012. Driving factors of a vegetation shift from Scots pine to pubescent oak in dry Alpine forests. Global Change Biology doi:10.1111/gcb.12038

Sala, A., Piper, F., Hoch, G. 2010. Physiological mechanisms of drought induced tree mortality are far from being resolved. New Phytologist 186:274-281.

Sánchez-Salguero, R., Navarro-Cerrillo, R.M., Camarero, J.J., FernándezCancio, A., Swetnam, T.W., Zavala, M.A. 2012. Vulnerabilidad frente a la sequía de repoblaciones de dos especies de pinos en su límite meridional en Europa. Ecosistemas 21(3):31-40.

Sangüesa-Barreda, G., Linares, J.C., Camarero, J.J. 2012. Mistletoe effects on Scots pine decline following drought events: insights from within-tree spatial patterns, growth and carbohydrates. Tree Physiology 32:585598.

Vicente-Serrano, S.M., Beguería, S., López-Moreno, J.I. 2010. A multiscalar drought index sensitive to global warming: The Standardized Precipitation Evapotranspiration Index. Journal of Climate 23:000.000.

Vicente-Serrano, S.M., Beguería, S., Lorenzo-Lacruz, J., Camarero, J.J., López-Moreno, J.I., Azorin-Molina, C., Revuelto, J., Morán-Tejeda, E., Sánchez-Lorenzo, A. 2012. Performance of drought indices for ecological, agricultural, and hydrological applications. Earth Interactions 16:127.

Williams, A.P., Allen, C.D., Macalady, A.K., Griffin, D., Woodhouse, C.A. Meko, D.M., Swetnam, T.W., Rauscher, S.A., Seager, R., GrissinoMayer, H.D., Dean, J.S., Cook, E.R., Gangodagamage, C., Cai, M., McDowell, N.G. 2012. Temperature as a potent driver of regional forest drought stress and tree mortality. Nature Climate Change doi:10.1038/nclimate1693.

Wilmking, M., Hallinger M., Van Bogaert, R., Kyncl, T., Babst, F., Hahne, W. Juday, G.P., de Luis, M., Novak, K., Völlm, C. 2012. Continuously missing outer rings in woody plants at their distributional margins. Dendrochronologia 30:213-222.

Woodall, C.W. 2008. When is one core per tree sufficient to characterize stand attributes? Results of a Pinus ponderosa case study. Tree-Ring Research 64: 50-60.

Yamaguchi, D.K. 1991. A simple method for crossdating increment cores from living trees. Canadian Journal of Forest Research 21:414-416. 